\title{
MicroRNA-320 inhibits cell proliferation, migration and invasion in retinoblastoma by targeting specificity protein 1
}

\author{
YUEHUA ZHAO, SHILIAN ZHANG and YONGFENG ZHANG \\ Department of Pediatrics, Affiliated Hospital of Weifang Medical University, Weifang, Shandong 261041, P.R. China
}

Received January 12, 2016; Accepted March 16, 2017

DOI: $10.3892 / \mathrm{mmr} .2017 .6767$

\begin{abstract}
Research into the expression and function of microRNAs (miRNAs/miR) in human cancer has provided novel insights into the molecular mechanisms underlying carcinogenesis and cancer progression. Aberrant miRNA expression has been reported in retinoblastoma $(\mathrm{RB})$ and several other types of human cancer. The present study demonstrated that miR-320 is significantly downregulated in RB tissues and cell lines. Furthermore, overexpression of miR-320 was demonstrated to inhibit proliferation, migration and invasion of RB cells. Bioinformatic analysis identified specificity protein 1 (SP1) as a potential target gene of miR-320. Luciferase reporter assay confirmed that the SP1 3'-untranslated region contains a direct binding site for miR-320, and restoration of miR-320 expression decreased the mRNA and protein expression levels of SP1. Notably, SP1 silencing induced a similar effect on the proliferation, migration and invasion of RB cells as that observed with miR-320 overexpression, further supporting the hypothesis that SP1 is a direct functional target of miR-320 in RB. In conclusion, these findings indicate that miR-320 may be an effective therapeutic target for the treatment of RB.
\end{abstract}

\section{Introduction}

Retinoblastoma (RB) is the most common childhood primary intraocular tumor (1). Most RB cases are diagnosed in children $<5$ years old (2); the incidence is $\sim 1: 15,000-20,000$ newborns worldwide (3). RB is classified into two groups: Hereditary and non-hereditary. Patients with hereditary RB account for $30-40 \%$ of cases and usually involve a positive family history, whereas cases with no family history are generally classified as non-hereditary (4-6). Previous studies have indicated that numerous risk factors contribute to RB

Correspondence to: Professor Yuehua Zhao, Department of Pediatrics, Affiliated Hospital of Weifang Medical University, 2428 Yuhe Road, Weifang, Shandong 261041, P.R. China

E-mail:wf_yuehuazhao@163.com

Key words: microRNA-320, retinoblastoma, SP1, growth, metastasis initiation and development, including genetic and epigenetic alterations to oncogenes and tumor suppressor genes $(7,8)$. Standard therapeutic treatments currently include enucleation and focal therapy, such as laser or cryotherapy, chemotherapy or radiotherapy (9). However, the 5-year overall survival rate for patients at advanced stages remains poor, mainly due to the development of local or distant metastases $(10,11)$. Therefore, investigating the underlying molecular mechanism responsible for RB carcinogenesis and progression may prove beneficial in the exploration of novel therapeutic strategies.

MicroRNAs (miRNAs/miR) are a group of small, highly conserved and non-protein-coding RNA molecules 18-23 nucleotides in length, which participate in the regulation of gene expression. Regulation occurs via semi-complementary binding to the 3'-untranslated regions (3'-UTRs) of target mRNAs, resulting in translational repression and/or mRNA degradation (12). These regulatory effects may be exerted over several cell types, targeting $~ 60 \%$ of human genes (13). miRNAs serve critical functions in the regulation of various oncogenic activities, including proliferation, angiogenesis, apoptosis, cell cycle progression, migration, invasion and metastasis (14-16). Recently, a large number of miRNAs have been identified as overexpressed or downregulated during the progression of human cancer, including RB, such as miR-31 (17), miR-204 (18) and miR-21 (19). Functionally, these miRNAs may serve either a tumor suppressing or promoting role in various types of human cancer, depending on whether they specifically target oncogenes or tumor suppressor genes (20). Therefore, these findings suggest that miRNAs may serve as potential therapeutic targets for the treatment of RB.

miR-320 has been studied in a number of human cancer types (21-23). However, the expression pattern and biological functions of miR-320 in RB remains unclear. The present study explored the expression levels of miR-320 in RB, and the results indicated that miR-320 expression levels were reduced in RB tissues and cell lines. The effects of miR-320 on the proliferation, migration and invasion of RB cells were also investigated. Functional studies indicated that miR-320 may act as a tumor suppressor, via inhibition of cell proliferation, migration and invasion of RB cells. Finally, specificity protein 1 (SP1) was identified as a direct target gene of miR-320 in RB. To the best of our knowledge, the present study is the first to investigate the expression, function and molecular mechanism of miR-320 in RB. 


\section{Materials and methods}

Human tissue samples. Normal retinal tissue $(\mathrm{n}=3,2$ males, 1 female; age, 26-67 years) and RB tissue ( $n=7,5$ males, 2 females; age, 14-53 years) samples were collected at the Affiliated Hospital of Weifang Medical University (Weifang, China) between August 2013 to June 2015. Tissues were obtained from patients that had undergone enucleation and had not received any other prior therapies, including chemotherapy, radiotherapy or local therapy. Normal retinal tissues were collected from patients with a ruptured globe. All tissue samples were snap-frozen in liquid nitrogen and stored at $-80^{\circ} \mathrm{C}$ prior to use. Patients provided written informed consent. The present study was approved by the ethics committee of the Affiliated Hospital of Weifang Medical University.

Cell lines, culture conditions and transfection. Human retinoblastoma cell lines (Y79, WERI-RB-1 and SO-RB50) and the HEK293T cell line were purchased from the American Type Culture Collection (Manassas, VA, USA), and maintained in RPMI-1640 medium (Gibco; Thermo Fisher Scientific, Inc., Waltham, MA, USA) supplemented with $10 \%$ fetal bovine serum (FBS; Gibco; Thermo Fisher Scientific, Inc.), $100 \mathrm{U} / \mathrm{ml}$ penicillin and $100 \mathrm{U} / \mathrm{ml}$ streptomycin. Cells were incubated in a humidified atmosphere at $37^{\circ} \mathrm{C}$ with $5 \% \mathrm{CO}_{2}$.

miR-320 mimic, negative control (NC), SP1 small interfering RNA (siRNA) and control siRNA were obtained from Shanghai GenePharma Co., Ltd. (Shanghai, China) with the following sequences: miR-320 mimic, 5'-AAAAGCUGG GUUGAGAGGGCGA-3'; NC mimic, 5'-UUCUCCGAACGU GUCACGUTT-3'; SP1 siRNA, 5'-GCAACAUGGGAAUUA UGAATT-3'; control siRNA, 5'-UUCUUCCGAACGUGU CACGUTT-3'. Cells were transfected with miR-320 mimics $(50 \mathrm{pmol} / \mathrm{ml}), \mathrm{NC}(50 \mathrm{pmol} / \mathrm{ml}), \mathrm{SP} 1$ siRNA $(50 \mathrm{pmol} / \mathrm{ml})$ or control siRNA $(50 \mathrm{pmol} / \mathrm{ml})$ using Lipofectamine 2000 (Invitrogen; Thermo Fisher Scientific, Inc.) and OPTI-MEM reduced serum medium (Gibco; Thermo Fisher Scientific, Inc.), according to the manufacturer's protocol.

Reverse transcription-quantitative polymerase chain reaction $(R T-q P C R)$. For miRNA and mRNA detection, total RNA from tissues and cells was isolated using TRIzol reagent (Invitrogen; Thermo Fisher Scientific, Inc.), according to the manufacturer's protocol. RNA concentration and quality was evaluated using a NanoDrop Spectrophotometer (NanoDrop; Thermo Fisher Scientific, Inc., Wilmington, DE, USA). To quantify miR-320 expression, reverse transcription was performed using a TaqMan MicroRNA Reverse Transcription kit (Applied Biosystems; Thermo Fisher Scientific, Inc.), according to the manufacturer's instructions. The relative expression of miR-320 was measured using a TaqMan miRNA assay (Applied Biosystems; Thermo Fisher Scientific, Inc.). The thermocycling conditions were as follows: 40 cycles of denaturation at $95^{\circ} \mathrm{C}$ for $15 \mathrm{sec}$ and annealing/extension at $60^{\circ} \mathrm{C}$ for $60 \mathrm{sec}$. The reaction system contained $1.0 \mu \mathrm{l}$ TaqMan miRNA assay (20X), $10.0 \mu \mathrm{l}$ TaqMan 2X Universal PCR Master Mix, $1.33 \mu \mathrm{l} \mathrm{cDNA}, 1 \mu \mathrm{l}$ forward primer and $1 \mu \mathrm{l}$ reverse primer and $5.67 \mu 1$ double distilled water. Small nuclear U6 RNA was used as an internal control for miR-320 expression. One Step SYBR PrimeScript ${ }^{\mathrm{TM}}$ RT-PCR kit II (Takara Biotechnology Co., Ltd.,
Dalian, China) was used to measure SP1 mRNA expression. The thermocycling conditions were as follows: $42^{\circ} \mathrm{C}$ for $5 \mathrm{~min}$, $95^{\circ} \mathrm{C}$ for $10 \mathrm{sec}$, then 40 cycles of $95^{\circ} \mathrm{C}$ for $5 \mathrm{sec}, 55^{\circ} \mathrm{C}$ for $30 \mathrm{sec}$ and $70^{\circ} \mathrm{C}$ for $30 \mathrm{sec}$. The reaction system contained $12.5 \mu 12 \mathrm{X}$ One Step SYBR ${ }^{\circledR}$ RT-PCR Buffer 4, $1.5 \mu 1$ Takara Ex Taq ${ }^{\mathrm{TM}}$ HS Mix, $0.5 \mu 1$ PrimeScript $^{\mathrm{TM}}$ PLUS RTase Mix, $1 \mu 1$ forward primer and $1 \mu \mathrm{l}$ reverse primer, $2 \mu \mathrm{l} \mathrm{cDNA}$ and $6.5 \mu \mathrm{l}$ double distilled water. The primers used in the present study were as follows: miR-302 forward, 5'-ACACTCCAGCTGGGAAAA GCTGGGTTGAGA-3' and reverse, 5'-TGGTGTCGTGGA GTCG-3'; U6 forward, 5'-CTCGCTTCGGCAGCACA-3' and reverse, 5'-AACGCTTCACGAATTTGCGT-3'; SP1 forward, 5'-TGTGAATGCTGCTCAACTCTCC-3' and reverse, 5'-CAT GTATTCCATCACCACCAG-3'; GAPDH forward, 5'-ACC ACAGTCCATGCCATCAC-3' and reverse, 5'-TCCACCACC CTGTTGCTGTA-3'. GAPDH was used as an internal control for SP1 mRNA expression. All experiments were performed in triplicate and the results were calculated using the $2^{-\Delta \Delta C q}$ method (24).

Cell proliferation assay. Cell proliferation of transfected cells was assessed using the Cell Counting Kit-8 (CCK-8; Dojindo Molecular Technologies, Inc., Kumamoto, Japan). Cells (3,000 cells/well) were seeded into 96-well plates, and transfected with miR-320 mimic, NC, SP1 siRNA or control siRNA as aforementioned. A cell proliferation assay was performed at various times points (24-96 h). Briefly, $10 \mu$ l CCK-8 reagent was added to the culture medium of each well, and the plates were incubated at $37^{\circ} \mathrm{C}$ for $2 \mathrm{~h}$, after which absorbance was measured at $450 \mathrm{~nm}$. All experiments were performed in triplicate.

Cell migration and migration assays. The migratory and invasive abilities of the transfected cells were evaluated using cell migration and invasion assays. For the cell migration assay, $1 \times 10^{5}$ transfected cells in $300 \mu$ l FBS-free medium were added into the upper chamber of a 24 -well Transwell ${ }^{\circledR}$ plate (pore size, $8 \mu \mathrm{m}$; Corning Incorporated, Corning, NY, USA), $500 \mu \mathrm{l}$ culture medium containing $20 \%$ FBS was added to the lower chamber. For the cell invasion assay, the membranes of a Transwell ${ }^{\circledR}$ plate were first coated with Matrigel ${ }^{\mathrm{TM}}$ (BD Biosciences, Franklin Lakes, NJ, USA). Transfected cells $\left(1 \times 10^{5} / 300 \mu \mathrm{l}\right)$ in FBS-free medium were added into the Matrigel ${ }^{\mathrm{TM}}$-coated Transwell ${ }^{\circledR}$ chambers, $500 \mu$ c culture medium supplemented with $20 \%$ FBS was subsequently added to the lower chamber to act as a chemoattractant. For both assays, the Transwell ${ }^{\circledR}$ chambers were incubated for $24 \mathrm{~h}$ following inoculation. Cells remaining on the filter surface of the upper chamber were carefully removed, and the cells that had migrated or invaded to the lower side of the chamber were fixed and stained with $0.5 \%$ crystal violet. The number of migrated and invaded cells were counted under a light microscope (Olympus IX53; Olympus Corporation, Tokyo, Japan).

Western blot analysis. SP1 and GAPDH expression levels were detected in total cell extracts of transfected cells by western blot analysis. A total of $72 \mathrm{~h}$ following transfection, cells were lysed with radioimmunoprecipitation assay buffer (Beyotime Institute of Biotechnology, Shanghai, China). A bicinchoninic acid protein assay kit (Pierce; Thermo Fisher Scientific, Inc.) was used to detect protein concentration, 
according to the manufacturer's instructions. Equal amounts of protein $(20 \mu \mathrm{g})$ were separated by $10 \%$ SDS-PAGE, transferred onto a polyvinylidene difluoride membrane (EMD Millipore, Billerica, MA, USA), and blocked with 5\% non-fat milk. The membranes were subsequently incubated with primary antibodies: Mouse anti-human SP1 monoclonal antibody $(1: 1,000 ;$ ab77441) or anti-GAPDH $(1: 1,000 ;$ ab9484) (both from Abcam, Tokyo, Japan) at $4^{\circ} \mathrm{C}$ overnight. Following three washes with Tris-buffered saline containing $0.05 \%$ Tween-20, the membranes were probed with goat anti-mouse HRP-conjugated secondary antibody (1:2,000; ab6789; Abcam). The protein blots were detected using the enhanced chemiluminescence western blotting kit (Pierce; Thermo Fisher Scientific, Inc.), according to the manufacturer's instructions and scanned using the GeneGnome HR Image Capture system (Syngene, Frederick, MD, USA). Relative expression levels of SP1 were normalized to GAPDH expression.

Bioinformatic analysis and luciferase reporter miRNA target validation. The potential targets and binding sites of miR-320 were predicted using TargetScan (http://www.targetscan.org/) and miRanda (http://www.microrna.org), which are databases that use different search algorithms.

To explore whether SP1 is a direct target gene of miR-320, a luciferase reporter assay was performed. pMIR-Report Luciferase vectors [pMIR-SP1-3'-UTR Wt (5'-AGAGGA UGAGCAGACCAGCUUUG-3') and pMIR-SP1-3'-UTR Mut (AGAGGAUGAGCAGACGUCGAAAG-3')] were purchased from Shanghai GenePharma Co., Ltd. HEK293T cells were seeded into 24 -well plates at $1.5 \times 10^{5}$ cells/well and subsequently transfected with miR-320 mimic or NC, and pMIR-SP1-3'-UTR Wt or pMIR-SP1-3'-UTR Mut, using Lipofectamine 2000, according to manufacturer's protocol. A total of $48 \mathrm{~h}$ post-transfection, Renilla and firefly luciferase activities were determined using a Dual-Luciferase reporter assay (Promega GmbH, Mannheim, Germany), according to the manufacturer's protocol. The experiments were independently performed in triplicate.

Statistical analysis. Data are presented as the mean \pm standard deviation of three repeated experiments. All data were analyzed using two-tailed Student's t-test or one-way analysis of variance, followed by the Student-Newman-Keuls post hoc test. Data were analyzed using SPSS 19.0 statistical software (SPSS IBM, Armonk, NY, USA). P<0.05 was considered to indicate a statistically significant difference.

\section{Results}

miR-320 expression is downregulated in $R B$. The expression levels of miR-320 were detected in RB and normal retinal tissues. The results of the RT-qPCR indicated that the expression levels of miR-320 were significantly decreased in RB tissues, compared with in normal retinal tissues $(\mathrm{P}<0.05$, Fig. $1 \mathrm{~A}$ and $\mathrm{B})$. The expression of miR-320 was also detected in RB cell lines (Y79, WERI-RB-1 and SO-RB50). Similarly, all three RB cell lines demonstrated decreased miR-320 expression, compared with normal retinal tissue $(\mathrm{P}<0.05$, Fig. $1 \mathrm{C})$. Taken together, these findings indicated that the expression levels of miR-320 were markedly decreased in RB tissues and cell lines.
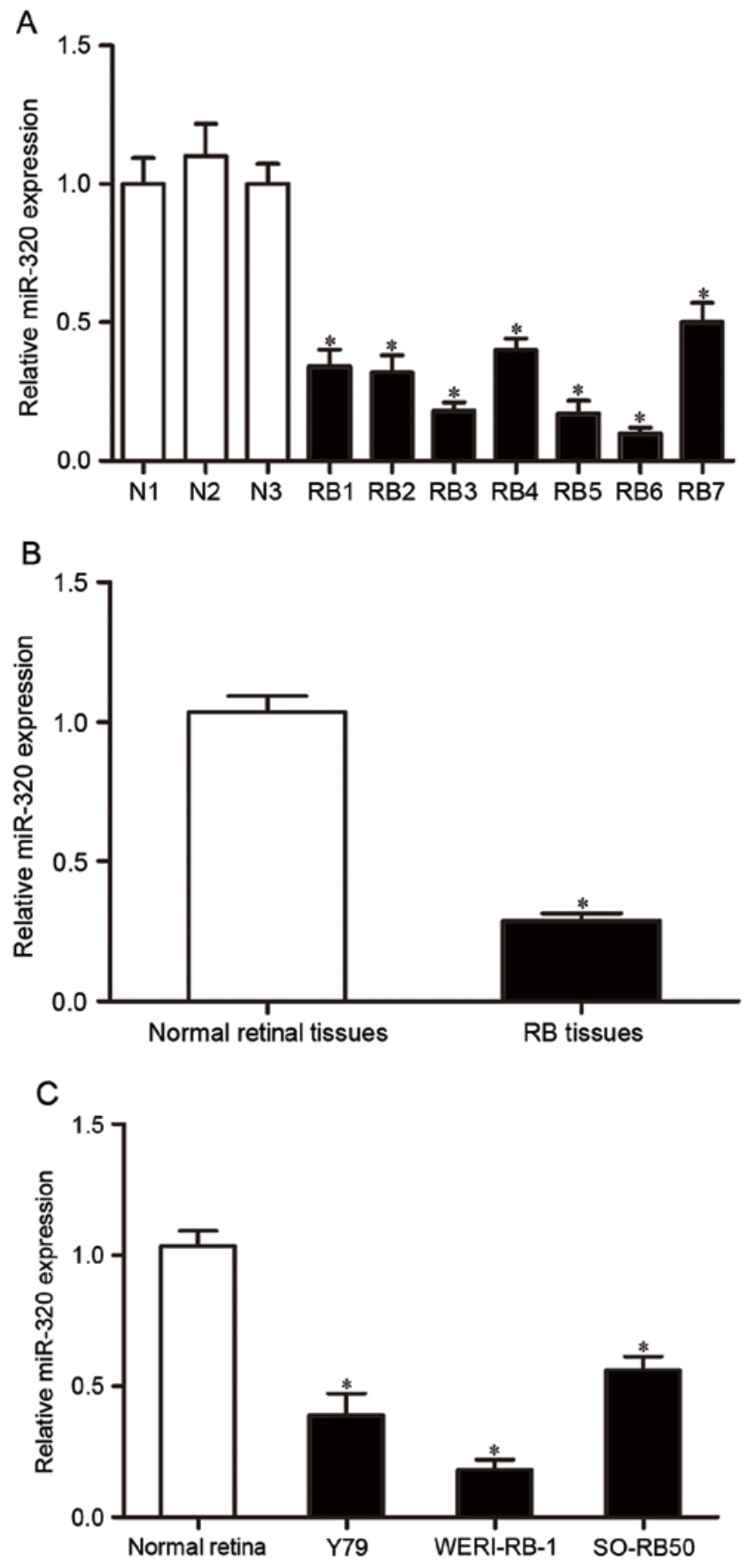

Figure 1. miR-320 expression is lower in RB tissues and cell lines. (A) Expression of miR-320 in RB and normal retinal tissues, as determined by reverse transcription-quantitative polymerase chain reaction. (B) The mean expression levels of miR-320 expression in RB and normal retinal tissues. (C) miR-320 was significantly downregulated in all three RB cell lines, compared with normal retinal tissues. Data are presented as the mean \pm standard deviation. ${ }^{*} \mathrm{P}<0.05$ vs. normal retinal tissues (control). $\mathrm{miR}$, microRNA; RB, retinoblastoma; N, normal.

miR-320 overexpression inhibits the proliferation, migration and invasion of RB cells. The Y79 and WERI-RB-1 cell lines demonstrated lower miR-320 expression compared with the SO-RB50 cell line; therefore, Y79 and WERI-RB-1 cells were selected for further studies. To explore the role of miR-320 in RB, Y79 and WERI-RB-1 cells were transfected with miR-320 mimic or NC, and miR-320 expression was validated; miR-320 expression was increased in both miR-320 

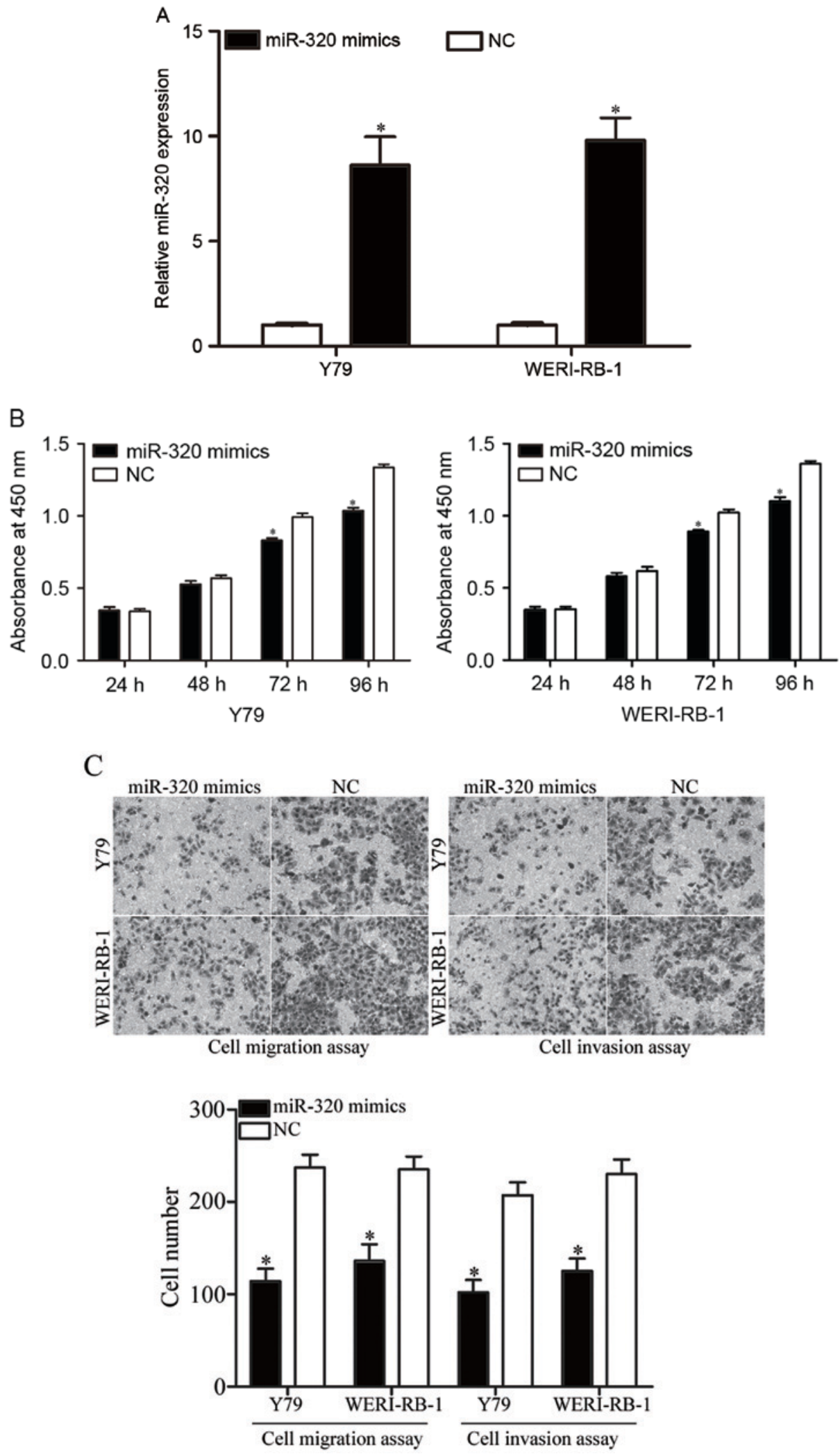

Figure 2. Overexpression of miR-320 inhibits the proliferation, migration and invasion of RB cells. (A) Expression of miR-320 in Y79 and WERI-RB-1 cells transfected with miR-320 mimic or NC. (B) miR-320 overexpression significantly inhibited the proliferation of Y79 and WERI-RB-1 cells compared with NC-transfected cells. (C) Transfection with miR-320 mimic significantly decreased cell migration and invasive abilities of Y79 and WERI-RB-1 cells, compared with NC-transfected cells (magnification, x200). Data are presented as the mean \pm standard deviation. "P<0.05 vs. NC. RB, retinoblastoma; miR, microRNA; NC, negative control.

mimic-transfected cell lines, compared with NC-transfected cells $(\mathrm{P}<0.05$, Fig. $2 \mathrm{~A})$. Cell proliferation, migration and invasion assays were performed to investigate the role of miR-320 in the growth and metastasis of RB cells. Analysis of cell proliferation indicated that miR-320 overexpression significantly inhibited the growth of Y79 and WERI-RB-1 cells, 
A

$\begin{array}{llc}\text { SP1 3'-UTR Wt } & 5 & \text {..AGAGGAUGAGCAGACCAGCUUUG... } \\ \text { hsa-miR-320 } & 3{ }^{\prime} & \text { AGCGGGAGAGUUGGGUCGAAAA } \\ \text { SP1 3'-UTR mut } & 5{ }^{\prime} & \text {...AGAGGAUGAGCAGACGUCGAAAG... }\end{array}$
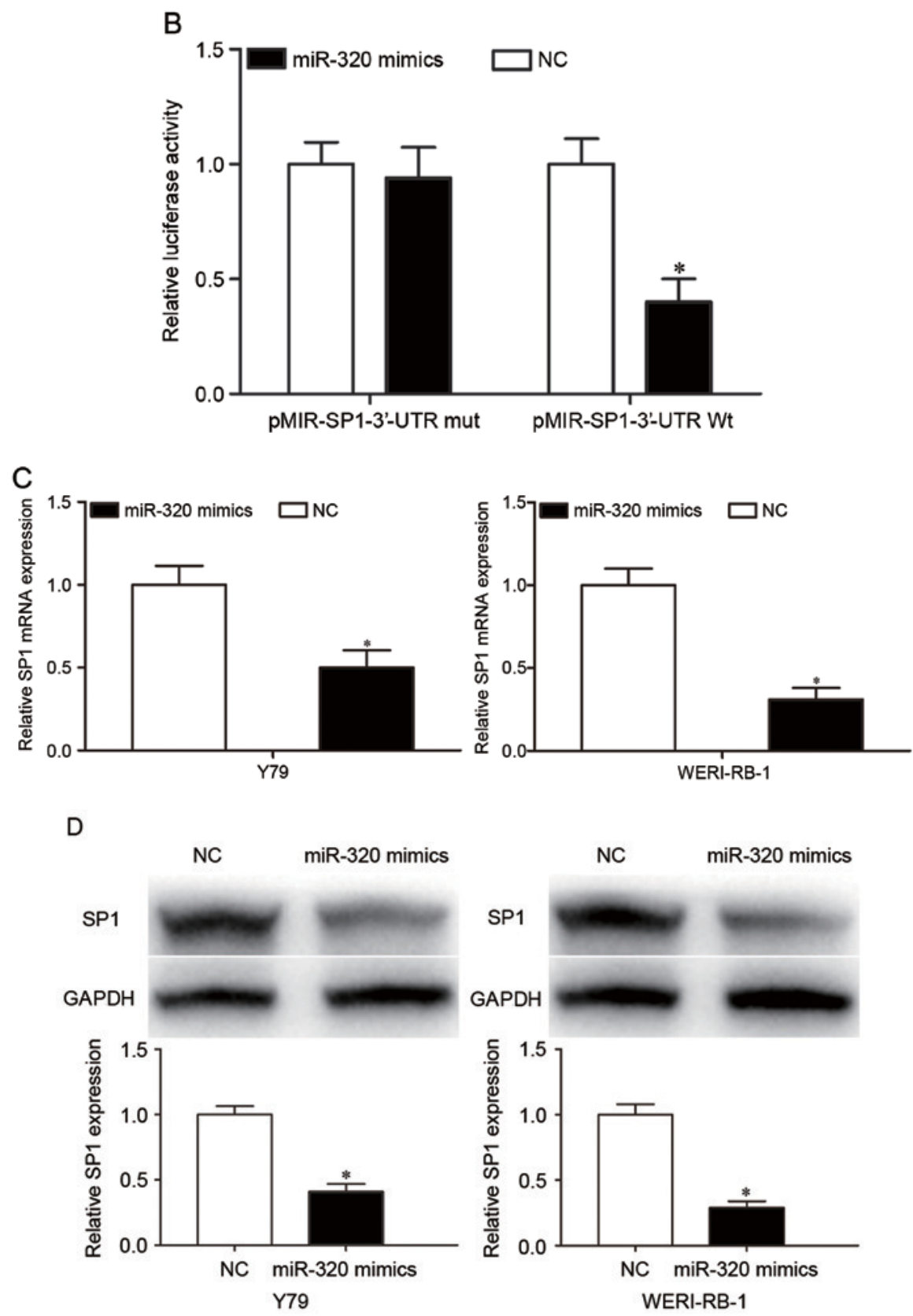

Figure 3. miR-320 directly targets SP1 3'-UTR in RB. (A) Predicted Wt and mut seed sites of miR-320 in SP1 3'-UTR. (B) Luciferase reporter assay indicated that miR-320 directly binds to the 3'-UTR of SP1. miR-320 overexpression significantly decreased SP1 expression at the (C) mRNA and (D) protein level in Y79 and WERI-RB-1 cells. Data are presented as the mean \pm standard deviation. "P<0.05 vs. NC. miR, microRNA; SP1, specificity protein 1; UTR, untranslated region; $\mathrm{RB}$, retinoblastoma; $\mathrm{NC}$, negative control; mut, mutant; $\mathrm{Wt}$, wild type.

compared with the NC-transfected cells $(\mathrm{P}<0.05$, Fig. 2B). Furthermore, miR-320 significantly decreased cell migration and invasion in Y79 and WERI-RB-1 cells, compared with NC-transfected cells $(\mathrm{P}<0.05$, Fig. $2 \mathrm{C})$. These results indicated that miR-320 may serve as a tumor suppressor in RB.

miR-320 directly targets SPI 3'-UTR in RB. To investigate the molecular mechanisms underlying the potential tumor suppressive abilities of miR-320, bioinformatic analysis was used to search for potential targets of miR-320. The analysis indicated that the 3'-UTR of SP1 contains a complementary site for the seed region of miR-320 (Fig. 3A). To explore whether the SP1 3'-UTR is a direct target of miR-320, a luciferase reporter assay was performed. The results demonstrated that the relative luciferase activities of pMIR-SP1-3'-UTR Wt were significantly inhibited following transfection with the 

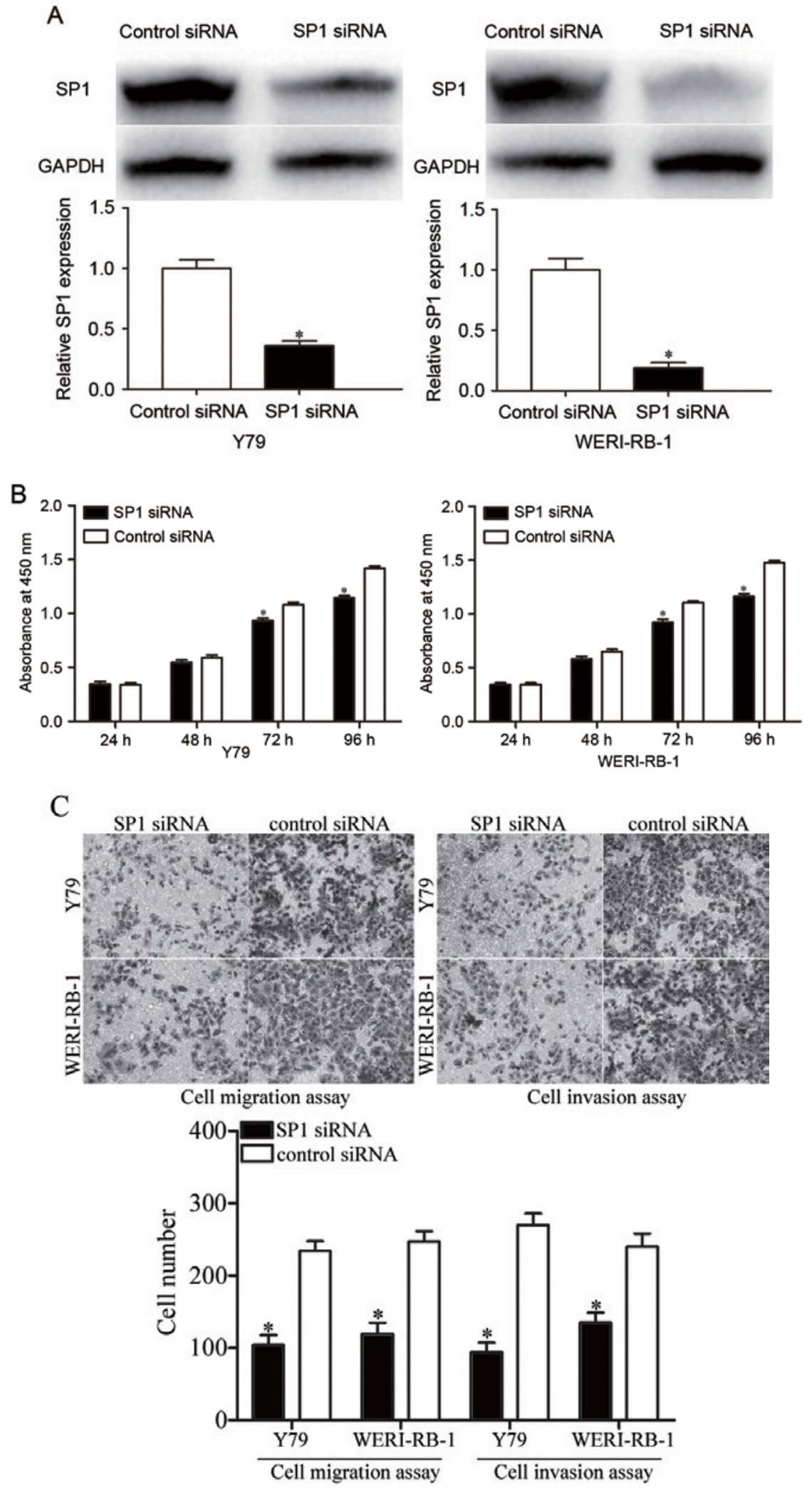

Figure 4. Silencing SP1 inhibits proliferation, migration and invasion of RB cells. (A) SP1 protein expression was measured in Y79 and WERI-RB1 cells transfected with SP1 siRNA or control siRNA. (B) Cell proliferation of Y79 and WERI-RB1 cells transfected with SP1 siRNA or control siRNA. (C) Cell migration and invasion assays of Y79 and WERI-RB1 cells transfected with SP1 siRNA or control siRNA (magnification, x200). Data are presented as the mean \pm standard deviation. ${ }^{*} \mathrm{P}<0.05$ vs. control. SP1, specificity protein 1; RB, retinoblastoma; siRNA, small interfering RNA.

miR-320 mimic, compared with the NC-transfected cells. However, transfection with pMIR-SP1-3'-UTR Mut abolished this suppression, demonstrating that miR-320 directly binds to the 3'-UTR of SP1 (Fig. 3B, P<0.05). Furthermore, the expression levels of SP1 were detected in Y79 and WERI-RB-1 cells following transfection with the miR-320 mimic. As indicated in Fig. 3C and D, miR-320 overexpression significantly decreased SP1 expression at the mRNA and the protein level, 
in Y79 and WERI-RB-1 cells $(\mathrm{P}<0.05)$. Collectively, these results indicated that SP1 may be a direct target gene of miR-320 in RB.

Effects of SP1 silencing on proliferation, migration and invasion of RB cells. To investigate the role of SP1 in RB cells, loss-of-function studies were performed using SP1 siRNA. Western blot analysis confirmed the knockdown of SP1; the results indicated that transfection with SP1 siRNA resulted in decreased SP1 protein expression in Y79 and WERI-RB1 cells ( $\mathrm{P}<0.05$, Fig. 4A), compared with control siRNA-transfected cells. To investigate the role of SP1, cell growth, migration and invasion were evaluated. Cell growth was significantly inhibited following transfection with SP1 siRNA, compared with cells transfected with control siRNA $(\mathrm{P}<0.05$, Fig. 4B). Furthermore, cell migration and invasion assays indicated that these functions were decreased by SP1 siRNA, compared with control siRNA-transfected cells ( $\mathrm{P}<0.05$, Fig. 4C). These results revealed that the effects of SP1 silencing on proliferation, migration and invasion of RB cells were similar to those induced by miR-320 overexpression, supporting the hypothesis that SP1 is a direct functional target of miR-320 in RB.

\section{Discussion}

Research has demonstrated that understanding the expression and functions of miRNAs may provide unique insights into the molecular mechanisms that underlie the carcinogenesis, and progression, of human cancer. Previous studies have detected abnormal expression profiles of miRNAs in RB carcinogenesis and development. Montoya et al reported that miR-31 and miR-200a regulate proliferation in RB (17). In addition, miR-204 has been reported to be downregulated in RB cells, and exhibited an ability to inhibit invasion and proliferation (18), whereas, Lei et al revealed that miR-101 may act as a tumor suppressor in RB (25).

The present study investigated the expression and function of miR-320 in RB tissues and cell lines. Analysis of miR-320 expression demonstrated significant miR-320 downregulation in $\mathrm{RB}$, suggesting that miR-320 may serve a role in RB progression. The biological functions of miR-320 were explored in the RB cell lines Y79 and WERI-RB-1, through analysis of cell proliferation, migration and invasion, post-transfection with miR-320 mimic or NC. The results of these analyses indicated that overexpression of miR-320 may inhibit the proliferation, migration and invasion of RB cells, thus suggesting that miR-320 may act as a tumor suppressor in the carcinogenesis and progression of RB.

Previous research regarding miR-320 has focused on glioma (21), colon cancer (22), osteosarcoma (23), oral cancer (26) and prostate cancer (27). Hsieh et al reported that miR-320 was downregulated in prostate cancer, and overexpression of miR-320 inhibited prostate cancer carcinogenesis in vitro and in vivo (27). In oral cancer, miR-320 was observed to be downregulated in tumor tissues and cell lines. Furthermore, ectopic miR-320 expression inhibited the migration, adhesion and tube formation of vascular endothelial cells in oral cancer, via the targeting of neuropilin-1 (NRP1) (26). Cheng et al demonstrated that miR-320 expression was reduced in osteosarcoma tissues; conversely, upregulation of miR-320 suppressed osteosarcoma cell proliferation via blockade of fatty acid synthase (FAS) (23). Sun et al reported that miR-320 was significantly reduced in glioma tissues, and miR-320 overexpression inhibited the proliferation and metastasis of glioma cells (21). Furthermore, miR-320 enhanced the sensitivity of human colon cancer cells to chemoradiotherapy, via modulation of forkhead box M1 (FOXM1) (22). These findings suggested that miR-320 serves a role in tumor suppression; further research should investigate the possibility of therapeutically targeting this miRNA in these specific types of cancer.

miRNAs have demonstrated an ability to regulate several physiological and pathological processes, via modulation of the expression of various target genes (28). Previous studies have indicated that miR-320 may target genes including E2F transcription factor 1 (21), FOXM1 (22), FAS (23), NRP1 (26) and cluster of differentiation 71 (29). The present study demonstrated that SP1 is a direct functional target of miR-320 in RB, and this was supported through several lines of evidence. Firstly, bioinformatic analysis demonstrated that SP1 contains a complementary site for the seed region of miR-320. Furthermore, upregulation of miR-320 decreased SP1 3'-UTR luciferase activity, an effect that was abolished by mutation of the miR-320 seed region. Secondly, miR-320 overexpression suppressed SP1 at mRNA and protein levels. Collectively, these results indicated that SP1 is a direct target gene of miR-320 in RB.

To further investigate the role of SP1 in RB, loss-of-function studies were performed using SP1 siRNA. The results demonstrated that SP1 knockdown suppressed proliferation, migration and invasion of RB cells, a response that was similar to the phenotype induced by miR-320 overexpression in RB. Taken together, these results suggested that the suppressive functions of miR-320 in RB may be partly mediated by suppression of SP1 expression. SP1 is a sequence-specific DNA-binding protein that encodes a protein of 785 amino acids (30). Functional studies have demonstrated that SP1 modulates numerous biological functions, including cell proliferation, differentiation, migration, metastasis and invasion (31-33). Notably, there are several SP1-targeting therapeutic compounds currently employed in the clinical management of cancer, with further compounds in development (34-37). The present study indicated that miR-320 targets SP1 to inhibit proliferation, migration and invasion of RB cells. Therefore, miR-320/SP1-based targeted therapy may represent a novel therapeutic strategy for the treatment of patients with RB.

In conclusion, the present study demonstrated the tumor suppressive role of miR-320 in human RB. miR-320 was significantly downregulated in RB tissues and cell lines, and restoration of miR-320 expression suppressed proliferation, migration and invasion of RB cells. Furthermore, SP1 was demonstrated to be a direct target of miR-320; miR-320-induced tumor suppressive roles may therefore be achieved via suppression of SP1, and miR-320 may represent a potential therapeutic target for the future treatment of RB.

\section{References}

1. Balmer A, Zografos L and Munier F: Diagnosis and current management of retinoblastoma. Oncogene 25: 5341-5349, 2006. 
2. Alonso J, Garcia-Miguel P, Abelairas J, Mendiola M and Pestaña A: A microsatellite fluorescent method for linkage analysis in familial retinoblastoma and deletion detection at the RB1 locus in retinoblastoma and osteosarcoma. Diagn Mol Pathol 10: 9-14, 2001.

3. Dimaras H, Kimani K, Dimba EA, Gronsdahl P, White A, Chan HS and Gallie BL: Retinoblastoma. Lancet 379: 1436-1446, 2012.

4. Kleinerman RA, Schonfeld SJ and Tucker MA: Sarcomas in hereditary retinoblastoma. Clin Sarcoma Res 2: 15, 2012.

5. Marees T, Moll AC, Imhof SM, de Boer MR, Ringens PJ and van Leeuwen FE: Risk of second malignancies in survivors of retinoblastoma: More than 40 years of follow-up. J Natl Cancer Inst 100: 1771-1779, 2008.

6. Moll AC, Imhof SM, Bouter LM and Tan KE: Second primary tumors in patients with retinoblastoma. A review of the literature. Ophthalmic Genet 18: 27-34, 1997.

7. Beta M, Venkatesan N, Vasudevan M, Vetrivel U, Khetan V and Krishnakumar S: Identification and insilico analysis of retinoblastoma serum microRNA profile and gene targets towards prediction of novel serum biomarkers. Bioinform Biol Insights 7: 21-34, 2013.

8. Wang J, Wang X, Wu G, Hou D and Hu Q: MiR-365b-3p, down-regulated in retinoblastoma, regulates cell cycle progression and apoptosis of human retinoblastoma cells by targeting PAX6. FEBS Lett 587: 1779-1786, 2013.

9. Friedman DL, Himelstein B, Shields CL, Shields JA, Needle M, Miller D, Bunin GR and Meadows AT: Chemoreduction and local ophthalmic therapy for intraocular retinoblastoma. J Clin Oncol 18: 12-17, 2000.

10. Shields CL and Shields JA: Diagnosis and management of retinoblastoma. Cancer Control 11: 317-327, 2004.

11. Xu X, Jia R, Zhou Y, Song X, Wang J, Qian G, Ge S and Fan X: Microarray-based analysis: Identification of hypoxia-regulated microRNAs in retinoblastoma cells. Int J Oncol 38: 1385-1393, 2011.

12. Iorio MV and Croce CM: MicroRNA dysregulation in cancer: Diagnostics, monitoring and therapeutics. A comprehensive review. EMBO Mol Med 4: 143-159, 2012.

13. Thieu W, Tilki D, deVere White RW and Evans CP: The role of microRNA in castration-resistant prostate cancer. Urol Oncol 32: $517-523,2014$

14. Reardon DA, Rich JN, Friedman HS and Bigner DD: Recent advances in the treatment of malignant astrocytoma. J Clin Oncol 24: 1253-1265, 2006.

15. Hwang HW and Mendell JT: MicroRNAs in cell proliferation, cell death, and tumorigenesis. Br J Cancer 96 (Suppl): R40-R44, 2007.

16. Calin GA, Ferracin M, Cimmino A, Di Leva G, Shimizu M, Wojcik SE, Iorio MV, Visone R, Sever NI, Fabbri M, et al: A MicroRNA signature associated with prognosis and progression in chronic lymphocytic leukemia. N Engl J Med 353: 1793-1801, 2005.

17. Montoya V, Fan H, Bryar PJ, Weinstein JL, Mets MB, Feng G, Martin J, Martin A, Jiang H and Laurie NA: Novel miRNA-31 and miRNA-200a-mediated regulation of retinoblastoma proliferation. PLoS One 10: e0138366, 2015.

18. Wu X, Zeng Y, Wu S, Zhong J, Wang Y and Xu J: MiR-204, down-regulated in retinoblastoma, regulates proliferation and invasion of human retinoblastoma cells by targeting CyclinD2 and MMP-9. FEBS Lett 589: 645-650, 2015.

19. Shen F, Mo MH, Chen L, An S, Tan X, Fu Y, Rezaei K, Wang Z, Zhang L and Fu SW: MicroRNA-21 Down-regulates Rb1 expression by targeting PDCD4 in retinoblastoma. J Cancer 5: 804-812, 2014.
20. Porkka KP,Pfeiffer MJ, Waltering KK, Vessella RL, Tammela TL and Visakorpi T: MicroRNA expression profiling in prostate cancer. Cancer Res 67: 6130-6135, 2007.

21. Sun JY, Xiao WZ, Wang F, Wang YQ, Zhu YH, Wu YF, Miao ZL and Lin YC: MicroRNA-320 inhibits cell proliferation in glioma by targeting E2F1. Mol Med Rep 12: 2355-2359, 2015.

22. Wan LY, Deng J, Xiang XJ, Zhang L, Yu F, Chen J, Sun Z, Feng M and Xiong JP: miR-320 enhances the sensitivity of human colon cancer cells to chemoradiotherapy in vitro by targeting FOXM1. Biochem Biophys Res Commun 457: 125-132, 2015.

23. Cheng C, Chen ZQ and Shi XT: MicroRNA-320 inhibits osteosarcoma cells proliferation by directly targeting fatty acid synthase. Tumour Biol 35: 4177-4183, 2014.

24. Livak KJ and Schmittgen TD: Analysis of relative gene expression data using real-time quantitative PCR and the 2(-Delta Delta C(T)) Method. Methods 25: 402-408, 2001.

25. Lei Q, Shen F, Wu J, Zhang W, Wang J and Zhang L: MiR-101, downregulated in retinoblastoma, functions as a tumor suppressor in human retinoblastoma cells by targeting EZH2. Oncol Rep 32: 261-269, 2014.

26. Wu YY, Chen YL, Jao YC, Hsieh IS, Chang KC and Hong TM: miR-320 regulates tumor angiogenesis driven by vascular endothelial cells in oral cancer by silencing neuropilin 1 . Angiogenesis 17: 247-260, 2014

27. Hsieh IS, Chang KC, Tsai YT, Ke JY, Lu PJ, Lee KH, Yeh SD, Hong TM and Chen YL: MicroRNA-320 suppresses the stem cell-like characteristics of prostate cancer cells by downregulating the Wnt/beta-catenin signaling pathway. Carcinogenesis 34: 530-538, 2013

28. Li M, Marin-Muller C, Bharadwaj U, Chow KH, Yao Q and Chen C: MicroRNAs: Control and loss of control in human physiology and disease. World J Surg 33: 667-684, 2009.

29. Schaar DG, Medina DJ, Moore DF, Strair RK and Ting Y: miR-320 targets transferrin receptor 1 (CD71) and inhibits cell proliferation. Exp Hematol 37: 245-255, 2009.

30. Chang WC and Hung JJ: Functional role of post-translational modifications of Sp1 in tumorigenesis. J Biomed Sci 19: 94, 2012.

31. Black AR, Black JD and Azizkhan-Clifford J: Sp1 and kruppel-like factor family of transcription factors in cell growth regulation and cancer. J Cell Physiol 188: 143-160, 2001

32. $\mathrm{Li} \mathrm{L}, \mathrm{He} \mathrm{S}$, Sun JM and Davie JR: Gene regulation by Sp1 and Sp3. Biochem Cell Biol 82: 460-471, 2004.

33. Mukhopadhyay D and Datta K: Multiple regulatory pathways of vascular permeability factor/vascular endothelial growth factor (VPF/VEGF) expression in tumors. Semin Cancer Biol 14 $123-130,2004$.

34. Liu S, Liu Z, Xie Z, Pang J, Yu J, Lehmann E, Huynh L, Vukosavljevic T, Takeki M, Klisovic RB, et al: Bortezomib induces DNA hypomethylation and silenced gene transcription by interfering with Sp1/NF-kappaB-dependent DNA methyltransferase activity in acute myeloid leukemia. Blood 111: 2364-2373, 2008

35. Chadalapaka G, Jutooru I, Chintharlapalli S, Papineni S, Smith R III, Li X and Safe S: Curcumin decreases specificity protein expression in bladder cancer cells. Cancer Res 68: 5345-5354, 2008

36. Pathi SS, Jutooru I, Chadalapaka G, Sreevalsan S, Anand S, Thatcher GR and Safe S: GT-094, a NO-NSAID, inhibits colon cancer cell growth by activation of a reactive oxygen species-microRNA-27a: ZBTB10-specificity protein pathway. Mol Cancer Res 9: 195-202, 2011.

37. Hsu TI, Wang MC, Chen SY, Huang ST, Yeh YM, Su WC, Chang WC and Hung JJ: Betulinic acid decreases specificity protein 1 (Sp1) level via increasing the sumoylation of $\mathrm{sp1}$ to inhibit lung cancer growth. Mol Pharmacol 82: 1115-1128, 2012. 